\title{
Effects of Common Origin and Common Rearing Environment on Variance in Ectoparasite Load and Phenotype of Nestling Alpine Swifts
}

\author{
P. Bize $\cdot$ A. Roulin
}

Received: 22 January 2009/Accepted: 21 May 2009/Published online: 6 June 2009

(C) Springer Science+Business Media, LLC 2009

\begin{abstract}
Knowledge of the quantitative genetics of resistance to parasitism is key to appraise host evolutionary responses to parasite selection. Here, we studied effects of common origin (i.e. genetic and pre-hatching parental effects) and common rearing environment (i.e. posthatching parental effects and other environment effects) on variance in ectoparasite load in nestling Alpine swifts (Apus melba). This colonial bird is intensely parasitized by blood sucking louse-flies that impair nestling development and survival. By cross-fostering half of the hatchlings between pairs of nests, we show strong significant effect of common rearing environment on variance $(90.7 \%$ in 2002 and $90.9 \%$ in 2003) in the number of louse-flies per nestling and no significant effect of common origin on variance in the number of louse-flies per nestling. In contrast, significant effects of common origin were found for all the nestling morphological traits (i.e. body mass, wing length, tail length, fork length and sternum length) under investigation. Hence, our study suggests that genetic and prehatching parental effects play little role in the distribution of parasites among nestling Alpine swifts, and thus that nestlings have only limited scope for evolutionary responses against parasites. Our results highlight the need to take into consideration environmental factors, including the evolution of post-hatching parental effects such as nest sanitation, in our understanding of host-parasite relationships.
\end{abstract}

P. Bize $(\bowtie) \cdot$ A. Roulin

Department of Ecology \& Evolution, Biophore, University

of Lausanne, 1015 Lausanne, Switzerland

e-mail: Pierre.Bize@unil.ch
Keywords Cost of parasitism - Crataerina melbae . Cross-fostering experiment $\cdot$ Heritability $\cdot$ Hippoboscidae . Host-parasite interaction · Parasite distribution

\section{Introduction}

In most organisms, there is considerable variation in the number of parasites present on a single host, some individuals being more infested than others (Shaw et al. 1998). Severe parasite infestation can greatly impair the development, reproduction and survival of their hosts, and therefore parasites are reckoned as an important selective force driving the evolution of hosts' behaviour, life history and population dynamics (Clayton and Moore 1997; Combes 2001). However, the direction and speed at which hosts evolve in response to parasite threats will depend on the mechanisms that generate inter-individual variance in parasite susceptibility. Three major mutually non-exclusive mechanisms have been advocated including (i) inter-individual variance in host genetic resistance, (ii) environmentally-induced variance in host phenotypic quality and (iii) parental effects associated with the transmission across generations of non-genetic factors affecting variance in offspring resistance such as nest sanitation behaviour.

Genetic variance among hosts in parasite susceptibility arises if parasite resistance is heritable, with some individuals lacking the necessary genes to resist parasite attacks. Until recently, genetics of parasite resistance has been the main concern of studies on host-parasite interactions (reviewed in Sorci et al. 1997; Greischar and Koskella 2007), an interest that takes its roots in coevolutionary models proposing a gene for gene arm race between hosts and parasites and, in turn, frequency-dependent selection of parasites on host genotypes (Red Queen dynamics; Jaenike 
1978; Hamilton 1980). It predicts that constant selection for adaptation and counter-adaptation leads to local adaptation of parasites to most common host genotypes until a new host mutation occurs and leads to a new equilibrium. In agreement with theoretical models, numerous studies, chiefly performed under laboratory condition, have revealed significant genetic variation in parasite susceptibility (e.g. Little and Ebert 2000; Dybdahl and Krist 2004; Tinsley et al. 2006), and concluded that hosts can quickly evolve anti-parasite strategies. The lack of general evidence for frequency-dependent selection in nature has nonetheless recently shed light on the importance of environmental factors, including parasite-induced parental effects, in mediating variation in host susceptibility to parasites (Ferguson and Read 2002; Blanford et al. 2003; Lambrechts et al. 2006; Roulin et al. 2007; Boulinier and Staszewski 2008; de Roode et al. 2008; but see Lively and Dybdahl 2000).

Environmentally-induced variance among hosts in parasite susceptibility occurs when environmental factors alter the expression of genetic resistance (i.e. heritability of phenotypic traits is usually higher in more favourable environments; Charmantier and Garant 2005) or, at the extreme, when environmental factors modulate host susceptibility independently of host genotype. For example, host nutrition and hormonal profile are two well-known modulators of resistance to parasites. Poorly fed hosts have usually fewer resources to allocate to parasite resistance (Wiehn and Korpimäki 1998; Krasnov et al. 2005), and androgen and stress hormones can be immunosuppressive (Müller et al. 2005). Furthermore, host genetic resistance is not the only factor shaping the distribution of parasites among hosts. Indeed, parasite fitness is modulated not only by their ability to evade host genetically-based resistance but also, for instance, by the amount and quality of food they can extract from their hosts (Ferguson and Read 2002; Lambrechts et al. 2006; Bize et al. 2008; de Roode et al. 2008) or by micro-climatic factors encountered on host body or in host local habitat (Heeb et al. 2000; Blanford et al. 2003; Laine 2008). Finally, one particular and important case of environmentally-induced variance in host resistance concerns parental effects where parents modulate offspring resistance to parasites (census Mousseau and Fox 1998; Wolf et al. 1998). For example, evidence is accumulating that mothers can protect their offspring against parasites by transmitting antibodies or other immune compounds to their offspring via the eggs in oviparous vertebrates and via the placenta and breast milk in mammals (Boulinier and Staszewski 2008; Gasparini et al. in press). In species with extensive parental care, parents may also reduce offspring exposure to parasites by grooming them (Christe et al. 1996) or by adding antiparasitic compounds in their nests (Petit et al. 2002;
Christe et al. 2003). Because susceptibility to parasites can differ between offspring, with for example male or junior offspring being less resistant to parasites than female and senior offspring (Christe et al. 1998; Tschirren et al. 2003), parental effects may also allow parents to finely adjust resistance to parasitism of the most susceptible individuals (Badyaev et al. 2006; Roulin et al. 2008). As a consequence, life-history stages, past development, resource levels, local climatic factors and parental effects have all the potential to mask the significance of inter-individual genetic variance in parasite susceptibility, and thereby to slow down the evolution of resistance in the wild. Understanding the influence of genetics, environmental and parental effects on host resistance is thus an important step toward the knowledge of host-parasite coevolution.

In the present study, we investigated genetics, environmental and parental effects on variance in the number of the blood-sucking louse-fly Crataerina melbae (Hippoboscidae; Diptera) parasitizing broods of the colonial Alpine swift Apus melba. This $7 \mathrm{~mm}$ long and flightless louse-fly feeds exclusively on the Alpine swift and can quickly move on foot between nests and hosts. This birdectoparasite system is particularly suitable for two reasons. First, because all the nests are infested by $C$. melbae (Bize et al. 2003), variation in louse-fly load between nests is expected to rely mostly on nestling compatibility (i.e. louse-flies prefer some hosts because, for instance, they can escape host defences or extract more resources, Bize et al. 2008) and only to a minor extent on variation in the likelihood that some hosts get in contact with louse-flies. Second, previous experimental studies have demonstrated that $C$. melbae negatively alters the development (Bize et al. 2003, 2004a) and survival (Bize et al. 2005) of nestlings and the long-term reproductive success of adult Alpine swifts (Bize et al. 2004b). Thus, in this system natural selection should favour the evolution of genetically resistant host strains, and in turn uphold the coevolutionary arm race between nestling swifts and louse-flies.

To study genetics, environmental and parental effects on variance in louse-fly load and phenotype of nestling Alpine swifts, we used a partial cross-fostering experimental design where half of hatchlings were swapped between pairs of nests. To account for possible spatial and temporal variation in host-parasite relationships (Lively 1999; Ardia and Rice 2006), we replicated this cross-fostering experiment in two different colonies distant by $21 \mathrm{~km}$ and over two different years. In birds, parents can modulate offspring resistance to parasites via parental effects taking place either before or after hatching. Pre-hatching parental effects can occur through the transmission from mothers to offspring of antibodies or other immuno-modulator compounds via the egg yolks (Boulinier and Staszewski 2008; Gasparini et al. in press), and post-hatching parental effects 
include grooming and nest sanitation behaviours by both parents (Christe et al. 1996; Petit et al. 2002). Because we swapped hatchlings between pairs of nests, variance in nestling phenotype associated with its nest of origin can be caused by genetic factors and/or pre-hatching parental effects, and variance in nestling phenotype associated with its nest of rearing can be caused by environmental factors and/or post-hatching parental effects. Hence, we predicted that, if host genotypes and/or pre-hatching parental effects explain significant differences among broods in parasite abundance, siblings raised in different nests should converge toward similar levels of infestation (i.e. significant effect of nestling origin). Alternatively, if environmental factors and/or post-hatching parental effects account for inter-brood variation in louse-fly loads, we predicted that nestlings of different origins raised in the same nest should converge toward similar levels of infestation (i.e. significant effect of nest of rearing). Because it has been found elsewhere that parasitized female Alpine swift nestlings have a higher mortality than parasitized male nestlings (Bize et al. 2005) and that first hatched Alpine swift nestlings are more heavily infested than last hatched siblings (Roulin et al. 2003), we also included nestling gender and hatching rank in the analyses. For comparison, we also analysed variance in nestling body mass and body size, traits that have been reported to show significant genetic additive variance in various bird species (e.g. Merilä 1996; Christe et al. 2000; Roulin et al. 2007).

\section{Material and Methods}

\section{Cross-Fostering Experiment}

We performed a partial cross-fostering experiment in 2002 and 2003 in two Alpine swift colonies located under the roofs of clock towers in Bienne (c. 100 breeding pairs) and Solothurn (c. 50 breeding pairs), Switzerland. Each year, nests were visited daily to determine laying date, clutch size, hatching date of the first egg (defined as day 0 ), brood size at hatching and hatching rank order. Young were individually recognised at hatching by marking them with non-toxic permanent colour markers, and at 10 days after hatching onwards by ringing them with an aluminium numbered ring. Experimental nests were matched in pairs by hatching date. Nests included in the experiment contained one to three hatchlings (eight nests with one hatchling, 50 nests with two hatchlings and 102 nests with three hatchlings). To ensure that all nestlings had hatched at the time of cross-fostering, we waited 2 days after the first young hatched (day 2). Then, we exchanged one nestling between pairs of nests of one to two nestlings, and two nestlings between pairs of nests of three nestlings. We matched exchanged nestlings by hatching rank, and exchanged last-hatched nestlings (hereafter referred to as 'junior' nestlings) as frequently as earlier-hatched senior siblings as shown by the fact that exchanged nestlings and non-exchanged siblings did not differ in wing length (paired $t$-tests $t_{\text {paired }}=0.14, n=152$ broods, $P=0.89$ ) and in body mass $\left(t_{\text {paired }}=0.15, n=152, P=0.88\right)$. Louse-flies rarely attack hatchlings, and therefore offspring were free of louse-flies at the start of the cross-fostering experiment (Bize et al. 2003; Roulin et al. 2003). In 2002 we swapped nestlings between 36 pairs of nests in Bienne and 18 pairs of nests in Solothurn, and in 2003 between nine pairs of nests in Bienne and 16 pairs of nests in Solothurn. We counted the number of louse-flies per nestling at 10, 20, 30 and 50 days after hatching, and then we computed a mean louse-fly load per nestling for the analyses. Separate analyses on louse-fly numbers counted at 10 , 20,30 and 50 days gave qualitatively similar results as analyses performed on mean values (results not shown). Louse-fly numbers counted at two successive age classes were inter-correlated (Pearson correlation between nestling louse-fly at 10 and 20 days: $r=0.16, n=259$ nestlings, $P=0.008$; 20 and 30 days: $r=0.51, n=166, P<0.001$; 30 and 50 days: $r=0.35, n=170, P<0.001)$ pointing out that nestling louse-fly load counted at one age was a reliable index of nestling infestation rate later in their development. At day 50, which is close before fledging, we weighed nestlings to the nearest $0.1 \mathrm{~g}$ and measured wing length, tail length and fork length to the nearest $\mathrm{mm}$ and sternum length to the nearest $0.1 \mathrm{~mm}$. Fork length is measured as the distance between the tips of the innermost and the outermost tail feathers. Measurements of nestling body size at day 50 provide reliable estimates of final body size (Pearson correlations between body traits of the same individuals measured at day 50 and in adulthood: wing length: $r=0.49, n=43, P<0.001$; tail length: $r=0.63$, $n=43, P<0.001$, fork length: $r=0.52, n=43, P<$ 0.001 ; sternum length: $r=0.96, n=41, P<0.001)$. There was no significant relationship between measures of body mass of the same individuals at day 50 and in adulthood $(r=0.05, n=43, P=0.74)$. At day 10 , a blood sample was collected from the wing vein of each nestling to sex the nestlings using blood cell DNA and molecular techniques (Bize et al. 2005).

\section{Statistics}

To partition effect due to the nest of origin and of the nest of rearing on nestling louse-fly load, body mass and body size, we computed mixed models where nestling sex and hatching rank in the nest of origin were entered as fixed factors, and where colony, pair of nests nested within the colony, nest of origin nested within pair of nests, nest of 
rearing nested within pair of nests, and the interaction between nest of origin and nest of rearing nested within the pair of nests where entered as random factors. Analyses were first performed separately for each year to explore annual variation. Data from both years were then pooled to increase our statistical power, with year being entered as a fixed factor. The term 'colony' accounts for phenotypic variation between colonies. The term 'pair of nests' accounts for phenotypic variation that is most likely attributable to seasonal effects. The term 'nest of origin' accounts for phenotypic variation due to shared genes and pre-hatching parental effects. The term 'nest of rearing' accounts for phenotypic variation due to a shared environment post-cross-fostering and to post-cross-fostering parental effects. The interaction 'origin*rearing' accounts for the fact that the distribution of louse-flies among families may differ among environments (i.e. nest of rearing), and thus can be considered as the genotype by environment interaction.

Variance components of random terms were estimated with the VARCOMP procedure in SAS (version 9.1, SAS institute Inc., Cary, NC, USA) using restricted maximum likelihood estimates and their significance levels were tested with the MIXED procedure using F-tests and type III sums of squares to control for unequal family sizes. We interpreted our variance components following Merilä (1996) (for a similar approach, see also Christe et al. 2000; Ardia and Rice 2006). Within each pair of nests, the variance component resulting from the term 'origin' estimates half the additive genetic variance $\left(1 / 2 V_{\mathrm{A}}\right)$ as well as a quarter of the dominant variance $\left(1 / 4 V_{\mathrm{D}}\right)$ and pre-hatching parental effects if present. We estimated $V_{\mathrm{A}}$ by doubling the variance due to the term 'origin'. The interaction 'origin*rearing' estimates the variance component due to the genotype by environment interaction $\left(V_{\mathrm{GE}}\right)$. The error variance estimates other environmental factors not attributable to the terms 'colony', 'pair of nests' and 'rearing', plus the remainder of $1 / 2 V_{\mathrm{A}}$ and $3 / 4 V_{\mathrm{D}}$. Environmental variance $\left(V_{\mathrm{E}}\right)$ is thus estimated as the sum of the variance components due to the terms 'colony', 'pair of nests', 'rearing' and the error variance minus $1 / 2 V_{\mathrm{A}}$ (i.e. $V_{\mathrm{E}}=$ $V_{\text {colony }}+V_{\text {pair }}$ of nest $\left.+V_{\text {rearing }}+\left(V_{\text {error }}-V_{\text {origin }}\right)\right)$. The total phenotypic variance $\left(V_{\mathrm{P}}\right)$ is calculated as the sum of $V_{\mathrm{A}}+V_{\mathrm{E}}+V_{\mathrm{GE}}$ (i.e. $V_{\mathrm{P}}=V_{\text {colony }}+V_{\text {pair of nest }}+V_{\text {origin }}$ $\left.+V_{\text {rearing }}+V_{\text {origin*rearing }}+V_{\text {error }}\right)$. We calculated narrow sense heritability as $h^{2}=V_{\mathrm{A}} / V_{\mathrm{P}}$ (Roff 1997). Here, note that $V_{\mathrm{A}}$, and in turn $h^{2}$, are estimations that will only prove reliable if $V_{\mathrm{D}}$ and maternal effects are negligible.

In the analyses we included only nestlings that survived up to 50 days of age. To estimate variation explained by the nests of origin and rearing, we included only the nests of rearing were at least two nest-mates were alive at day 50 and the nests of origin were at least two siblings were alive at day 50. Therefore, final analyses were performed on 194 nestlings from 82 broods in 2002 and 79 nestlings from 30 broods in 2003. Mean louse-fly load Y was Box-Cox $(\mathrm{Y}+1)$ transformed before analyses to fit a normal distribution. Box-Cox transformation of mean louse-fly load was done in JMP IN 7.0 (SAS institute Inc., Cary, NC, USA), and all other analyses were performed in SAS 9.1.

\section{Results and Discussion}

The understanding of variation in parasite abundance among hosts is important because high parasite loads can greatly impair hosts' survival and reproductive success, and in turn the number of host gene copies passed on to the following generations (Combes 2001). Exchanging half of the hatchlings between pairs of nests pointed out that the nest of origin did not explain a significant part of variation in louse fly abundance among nestling Alpine swifts (Tables 1 and 2). In other words, siblings raised in different nests were not similarly infested (Fig. 1), and hence nestling genetic characteristics and pre-hatching parental effects were poor predictors of parasite loads. The nest of rearing accounted for a large part of the variation $(52.9 \%$ in 2002 and $67.3 \%$ in 2003) in louse-fly abundance (Tables 1 and 2), indicating that unrelated nest-mates sharing the same environment had a similar number of ectoparasites on their plumage (Fig. 1). Experimental evidence for heritable variation in ectoparasite abundance in wild birds are restricted to mite and chewing louse abundance in barn swallows Hirundo rustica (Møller 1990; Møller et al. 2004) and fly abundance in barn owls Tyo alba (Roulin et al. 2007). At least six hypotheses can explain apparent lack of heritable variation in louse-fly abundance in nestling Alpine swifts.

First, ontogenetic constraints may prevent the full expression of resistant genes in nestlings if, for example, the immune system of nestling Alpine swifts is immature and poorly functional. However, the facts that we measured nestling parasite load over a 50-day-period and that nestling immunity was previously shown to shape louse-fly blood meal size (Bize et al. 2008) is not consistent with this hypothesis. To formally address this issue, studies about heritable variation in parasite load of adult Alpine swifts are required.

Second, there is increasing evidence that the heritability of phenotypic traits is usually higher in more favourable environments (Charmantier and Garant 2005), and thus poor environmental condition may have prevented us to detect significant effect of the nest of origin on nestling louse-fly load. To control for possible temporal and spatial environmental factors we replicated our cross-fostering experiment over 2 years (i.e. 2002 and 2003) and in two 


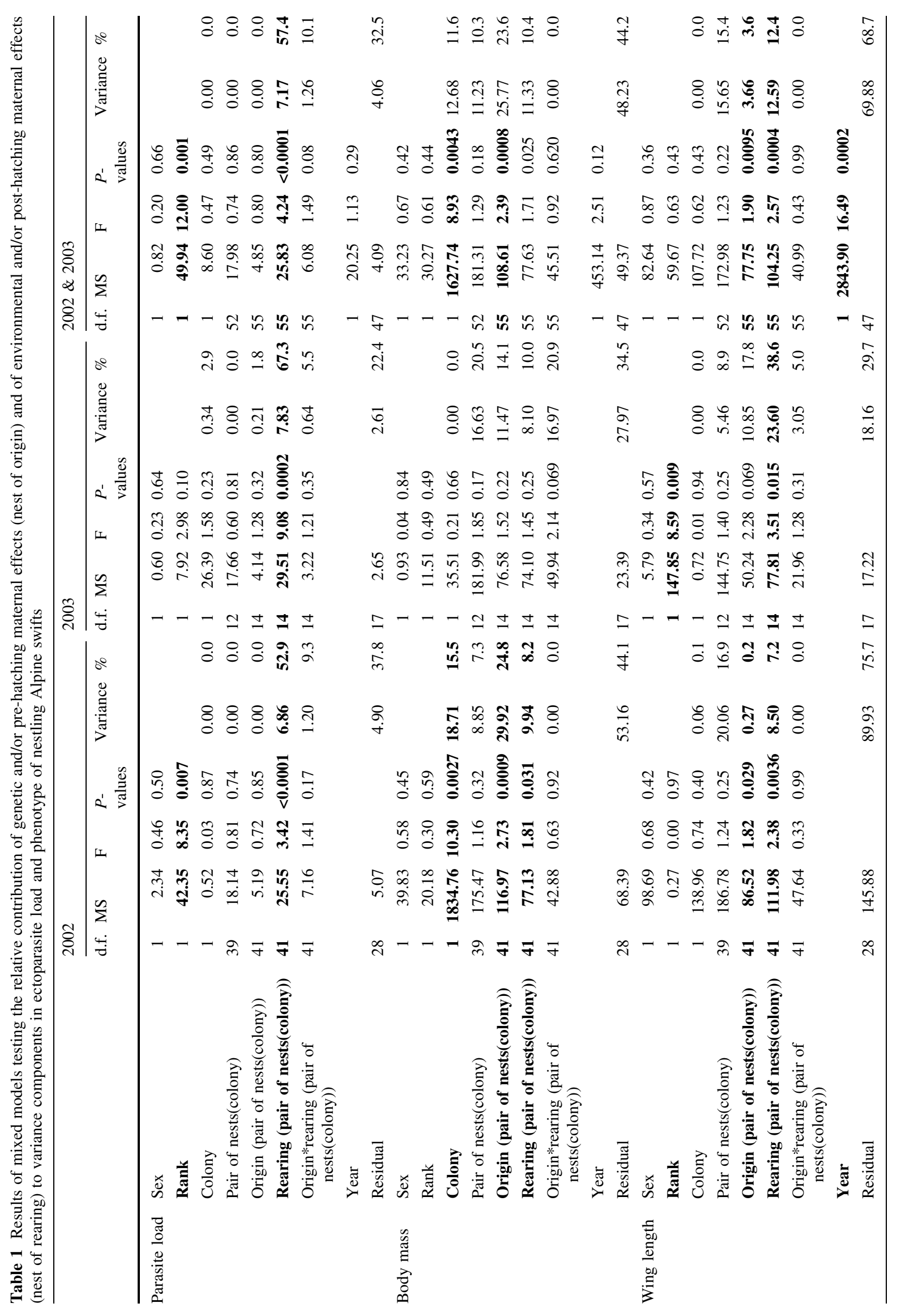




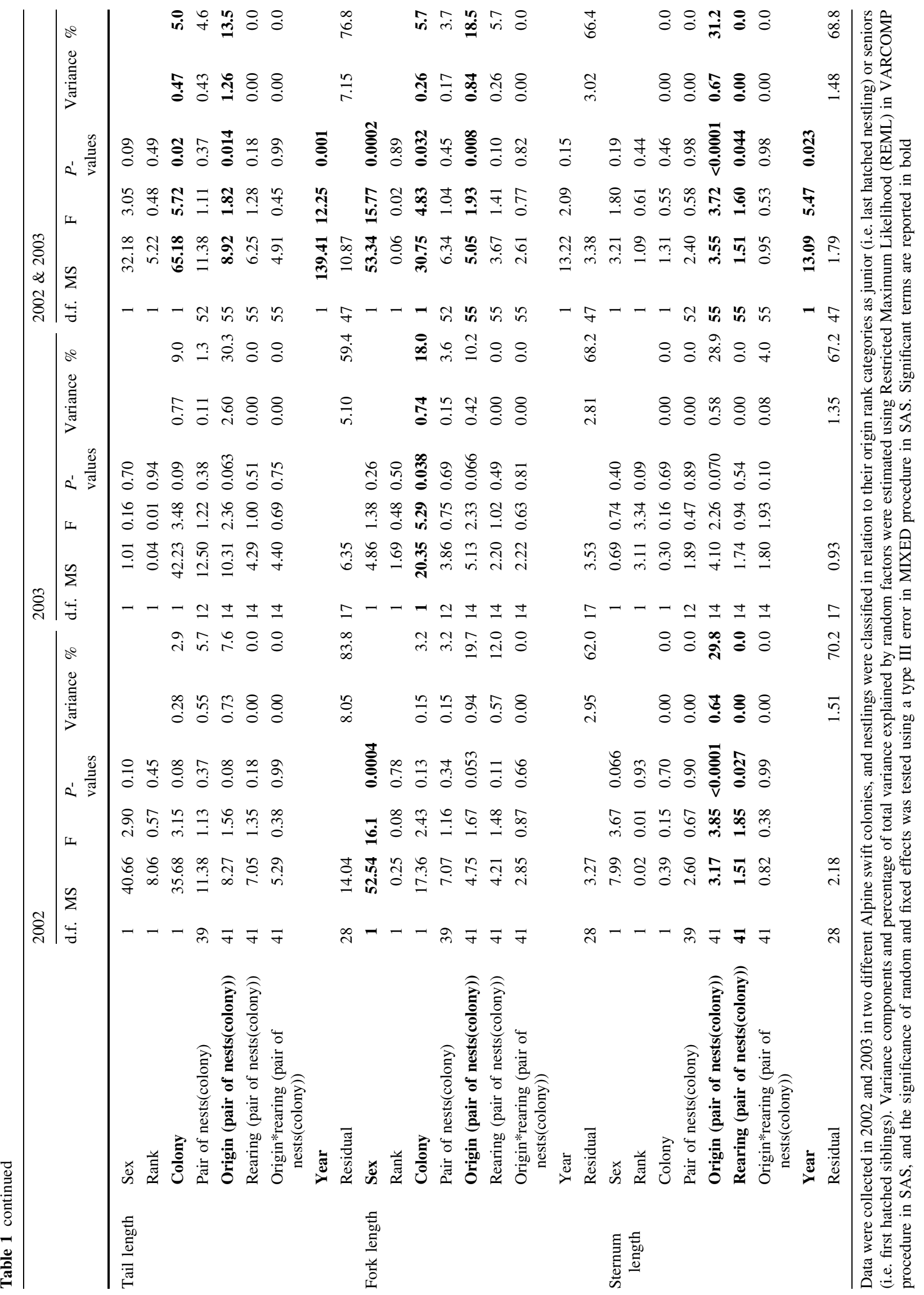


Table 2 Phenotypic $\left(V_{\mathrm{P}}\right)$; environmental $\left(V_{\mathrm{E}}\right)$; additive $\left(V_{\mathrm{A}}\right)$ and genotype by environment interaction $\left(V_{\mathrm{GE}}\right)$ components of variance in ectoparasite load and phenotype in nestling Alpine swifts measured in two different years (2002 and 2003)

\begin{tabular}{|c|c|c|c|c|c|c|c|c|c|c|}
\hline & & $V_{\mathrm{P}}$ & $\%$ & $V_{\mathrm{E}}$ & $\%$ & $V_{\mathrm{A}}$ & $\%$ & $V_{\mathrm{GE}}$ & $\%$ & $h^{2}$ \\
\hline \multirow[t]{3}{*}{ Parasite load } & 2002 & 12.96 & 100.0 & 11.76 & 90.7 & 0.00 & 0.0 & 1.20 & 9.3 & 0.00 \\
\hline & 2003 & 11.63 & 100.0 & 10.57 & 90.9 & 0.42 & 3.6 & 0.64 & 5.5 & 0.04 \\
\hline & $2002 \& 2003$ & 12.49 & 100.0 & 11.23 & 89.9 & 0.00 & 0.0 & 1.26 & 10.1 & 0.00 \\
\hline \multirow[t]{3}{*}{ Body mass } & 2002 & 120.58 & 100.0 & 60.74 & 50.4 & 59.84 & 49.6 & 0.00 & 0.0 & 0.50 \\
\hline & 2003 & 81.14 & 100.0 & 41.23 & 50.8 & 22.94 & 28.3 & 16.97 & 20.9 & 0.28 \\
\hline & $2002 \& 2003$ & 109.24 & 100.0 & 57.70 & 52.8 & 51.54 & 47.2 & 0.00 & 0.0 & 0.47 \\
\hline \multirow[t]{3}{*}{ Wing length } & 2002 & 118.82 & 100.0 & 118.28 & 99.5 & 0.54 & 0.5 & 0.00 & 0.0 & 0.00 \\
\hline & 2003 & 61.12 & 100.0 & 36.37 & 59.5 & 21.70 & 35.5 & 3.05 & 5.0 & 0.36 \\
\hline & $2002 \& 2003$ & 101.78 & 100.0 & 98.12 & 96.4 & 3.66 & 3.6 & 0.00 & 0.0 & 0.04 \\
\hline \multirow[t]{3}{*}{ Tail length } & 2002 & 9.61 & 100.0 & 8.15 & 84.8 & 1.46 & 15.2 & 0.00 & 0.0 & 0.15 \\
\hline & 2003 & 8.58 & 100.0 & 3.38 & 39.4 & 5.20 & 60.6 & 0.00 & 0.0 & 0.61 \\
\hline & $2002 \& 2003$ & 9.31 & 100.0 & 6.79 & 72.9 & 2.52 & 27.1 & 0.00 & 0.0 & 0.27 \\
\hline \multirow[t]{3}{*}{ Fork length } & 2002 & 4.76 & 100.0 & 2.88 & 60.5 & 1.88 & 39.5 & 0.00 & 0.0 & 0.39 \\
\hline & 2003 & 4.12 & 100.0 & 3.28 & 79.6 & 0.84 & 20.4 & 0.00 & 0.0 & 0.20 \\
\hline & $2002 \& 2003$ & 4.55 & 100.0 & 2.87 & 63.1 & 1.68 & 36.9 & 0.00 & 0.0 & 0.37 \\
\hline \multirow[t]{3}{*}{ Sternum length } & 2002 & 2.15 & 100.0 & 0.87 & 40.5 & 1.28 & 59.5 & 0.00 & 0.0 & 0.60 \\
\hline & 2003 & 2.01 & 100.0 & 0.77 & 38.3 & 1.16 & 57.7 & 0.08 & 4.0 & 0.58 \\
\hline & $2002 \& 2003$ & 2.15 & 100.0 & 0.81 & 37.7 & 1.34 & 62.3 & 0.00 & 0.0 & 0.62 \\
\hline
\end{tabular}

The narrow sense heritability $\left(h^{2}\right)$ is calculated as $V_{\mathrm{A}} / V_{\mathrm{P}}$

colonies, and it has been shown elsewhere that one of the two years (i.e. 2003) provided a year of prime weather conditions and in turn rearing condition for nestling Alpine swifts (Bize et al. 2006). The fact that we found significant effect of the nest of origin on all five nestling morphological traits (Table 1; Fig. 1), and no significant effect of the nest of origin on nestling louse-fly load (Table 1) reinforces the idea that nestling origin plays apparently little importance in the distribution of louse-flies between nestling hosts whatsoever the variation in environmental condition. Heritability of nestling morphological traits ranged from 0.04 to 0.62 (Table 2; Fig. 1), thus resulting in low to high narrow sense heritability that are comparable to previous field studies in birds (e.g. Merilä 1996; Christe et al. 2000; Roulin et al. 2007).

Third, if parasites have only negligible consequences on the fitness of their hosts, selection exerted on hosts to evolve defence mechanisms may be weak. However, this possibility is unlikely because previous experiments where the number of louse-flies per brood was manipulated have demonstrated significant detrimental effects of C. melbae on development (Bize et al. 2003, 2004a) and reproductive success (Bize et al. 2004b) in the Alpine swift.

Fourth, if parasite-induced selection on host fitness is intense, genetic variance for parasite resistance may be depleted (Mousseau and Roff 1986), a process that can be further exacerbated if hosts show low dispersal rates and concomitant gene flows. Given that the louse-fly C. melbae induces substantial fitness costs and that the Alpine swift shows moderate to high natal philopatry (Arn 1960), we may have failed to detect significant heritable parasite resistance because genetic variation coding for this trait was depleted within colonies. To test this issue, experiments are required where effects of host genetics on parasite resistance are investigated at a larger evolutionary scale by comparing, for example, the performance of louseflies issued from one colony among hosts of various colonies, thus testing for local adaptation in this bird-louse-fly system (e.g. McCoy et al. 2002). It is worth noting here that genetic variation for parasite resistance and response to selection are related to effective population size (Falconer and Mackay 1996). Although we have little information on effective population sizes of wild birds, surveys of Western European bird populations give estimates of 62'000 Alpine swifts, 170'000 barn owls and 19'000'000 barn swallows (Hagemeijer and Blair 1997). Thus, the apparent lack of heritable variation in louse-fly abundance in nestling Alpine swifts when compared to the other bird species (Møller 1990; Møller et al. 2004; Roulin et al. 2007) may also arise from an erosion of the genetic diversity for parasite resistance in small bird populations.

Fifth, the effect of nest of origin accounts not only for genetic effects but also for pre-hatching parental effects. Evidence is increasing that pre-hatching parental effects can allow parents to finely adjust their offspring phenotype to prevailing environmental condition (Mousseau and Fox 

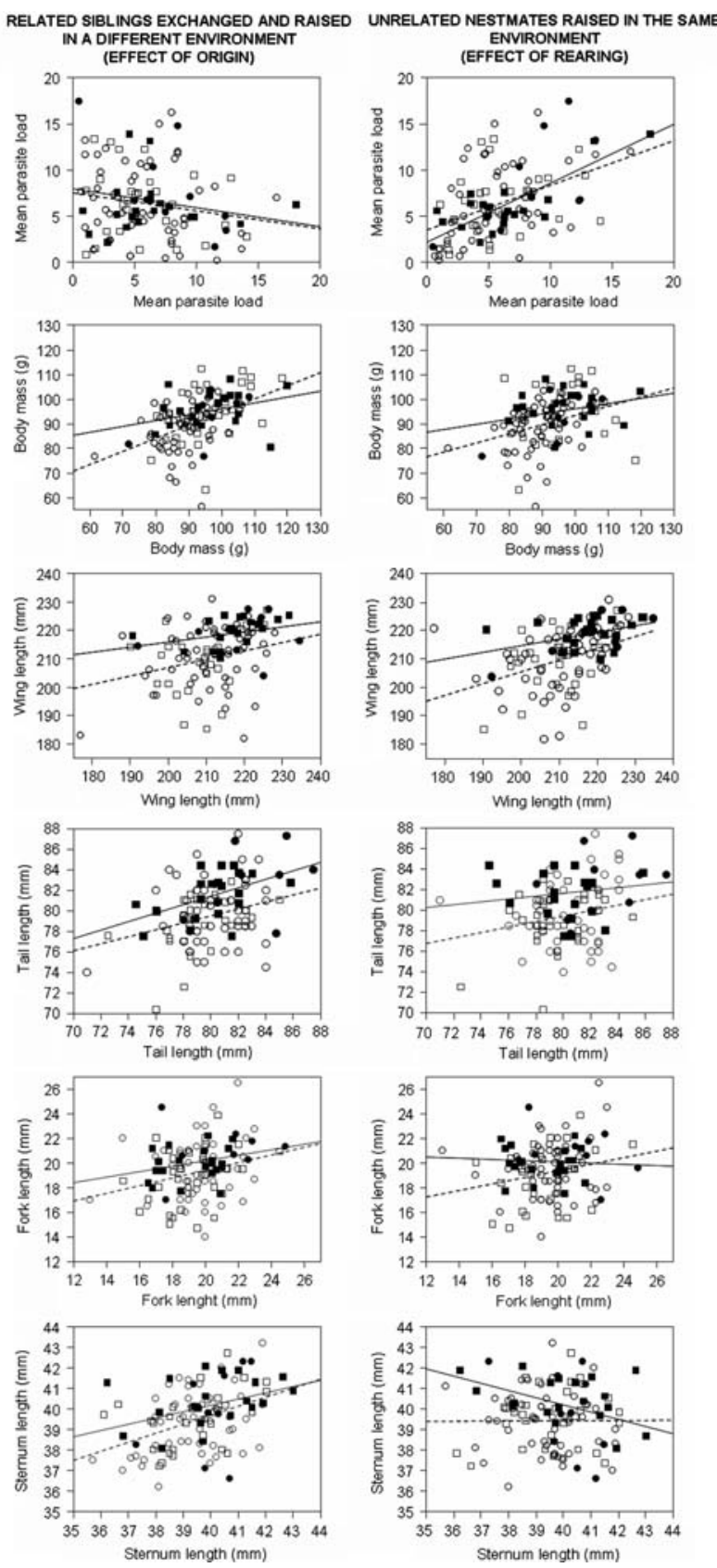

Fig. 1 Phenotypic variation of sibling Alpine swifts reared in two different nests (graphics on the left) illustrating the effect of common origin on offspring phenotype; and phenotypic variation of nest-mate Alpine swifts that were of two different origins but reared in the same nest (graphics on the right) illustrating the effect of rearing environment. Data were collected in 2002 (open symbol and dashed line) and 2003 (closed symbol and solid line) in the colonies Bienne (circle) and Solothurn (square)

1998), and biased pre-hatching parental effect may substantially reduce sibling resemblance and, in turn, the probability to detect a significant effect of the nest of origin on nestling phenotype. Previous studies have shown that susceptibility of nestling Alpine swifts to the louse-fly
C. melbae varies with nestling sex and hatching rank (Roulin et al. 2003; Bize et al. 2005). Therefore, to control for possible sex-biased and rank-biased parental effects on offspring resistance (e.g. Badyaev et al. 2006; Roulin et al. 2008), we accounted in our statistical analyses for the effect of nestling sex and hatching rank when studying the effect of nest of origin and nest of rearing on nestling variance in louse-fly load. In agreement with previous results, we found that first-hatched nestlings were more infested than lasthatched ones (significant effect of nestling rank in Table 1; see also Roulin et al. 2003), and that male and female offspring were similarly infested (no significant of nestling sex in Table 1; see also Bize et al. 2005). The lack of significant effect of nestling origin on parasite load, despite controlling for potential biased pre-hatching parental effects, underlines again the apparent minor importance of genetic effects on nestling resistance to parasites.

Finally, even if nestling resistance to parasites has a genetic basis, it can be overwhelmed by non-genetic factors and post-hatching parental effects, as suggested by the strong determinant of the nest of rearing on nestling lousefly load in two distinct years (Table 1). This major effect of the nest of rearing on nestling louse-fly load highlights the importance to take into consideration environmental and post-hatching parental effects in host-parasite studies, which are two factors that have received little attention in comparison to genetic and pre-hatching parental effects. Thus, more work is now required to establish which factors, environmental and/or parental, are responsible for the striking differences in louse-fly abundance among Alpine swift nests. To appraise the relative importance of environmental effects in shaping variation in louse-fly abundance among nests, information needs to be collected on louse-fly life history cycles and ecological requirements. To appraise the relative importance of post-hatching parental effects in shaping variation in louse-fly abundance among nests, information are required for example about the efficiency of grooming behaviours in controlling ectoparasite load (Clayton et al. 1999; 2005) and about heritable variation in parental grooming efficiency.

In conclusion, we report significant environmental variance, but no apparent significant additive genetic variance, in the number of louse-flies C. melbae per nestling Alpine swifts. Thus, these findings suggest limited scope for evolutionary responses against parasites by nestling Alpine swifts. Because post-hatching parental effects, such as grooming and nest sanitation, may account for part of the large environmental variance in louse-fly load among nests reported in the present study, and because parental grooming and nest sanitation behaviours may show heritable variation, future studies have to establish the potential for evolutionary responses against parasites by parent rather than nestling Alpine swifts. 
Acknowledgements We thank Dominik Pfluger and the late Theo Marbot for allowing us to access the colonies, the Swiss National Science Foundation for support (grants $n^{\circ}$ PP00A-109009 to PB and $\mathrm{n}^{\circ}$ PP00A-102913 to AR), and two anonymous referees for helpful comments. Cross-fostering experiments were carried out under the authorization of the Veterinary Offices of the Cantons Bern and Solothurn.

\section{References}

Ardia, D. R., \& Rice, E. B. (2006). Variation in heritability of immune function in the tree swallow. Evolutionary Ecology, 20, 491-500.

Arn, H. (1960). Biologische Studien am Alpensegler. Solothurn, Switzerland: Verlag Vogt-Schild AG.

Badyaev, A. V., Hamstra, T. L., Oh, K. P., \& Acevedo Seaman, D. A. (2006). Sex-biased maternal effects reduce ectoparasite-induced mortality in a passerine bird. Proceeding of the National Academy of Sciences of the United States of America, 103, 14406-14411.

Bize, P., Jeanneret, C., Klopfenstein, A., \& Roulin, A. (2008). What makes a host profitable? Experimental evidence that parasites balance host nutritive resources against immunity. American Naturalist, 171, 107-118. doi:10.1086/523943.

Bize, P., Metcalfe, N. B., \& Roulin, A. (2006). Catch up growth strategies differ between body structures: Interactions between age and structure-specific growth in wild nestling Alpine swifts. Functional Ecology, 20, 857-864. doi:10.1111/j.1365-2435. 2006.01157.x.

Bize, P., Roulin, A., Bersier, L.-F., Pfluger, D., \& Richner, H. (2003). Parasitism and developmental plasticity in Alpine swift nestlings. Journal of Animal Ecology, 72, 633-639. doi: 10.1046/j.1365-2656.2003.00734.x.

Bize, P., Roulin, A., \& Richner, H. (2004a). Parasitism, developmental plasticity and bilateral asymmetry of wing feathers in Alpine swift (Apus melba) nestlings. Oikos, 106, 317-323. doi: 10.1111/j.0030-1299.2004.13019.x.

Bize, P., Roulin, A., Tella, J. L., Bersier, L.-F., \& Richner, H. (2004b). Additive effects of ectoparasites over the reproductive attempts in the long-lived Alpine swifts. Journal of Animal Ecology, 73, 1080-1088. doi:10.1111/j.0021-8790.2004.00880.x.

Bize, P., Roulin, A., Tella, J. L., \& Richner, H. (2005). Female-biased mortality in experimentally parasitized Alpine swift Apus melba nestlings. Functional Ecology, 19, 405-413. doi:10.1111/j. 1365-2435.2005.00995.x.

Blanford, S., Thomas, M. B., Pugh, C., \& Pell, J. K. (2003). Temperature checks the Red Queen? Resistance and virulence in a fluctuating environment. Ecology Letters, 6, 2-5. doi: 10.1046/j.1461-0248.2003.00387.x.

Boulinier, T., \& Staszewski, V. (2008). Maternal transfer of antibodies: Raising immuno-ecology issues. Trends in Ecology \& Evolution, 23, 282-288. doi:10.1016/j.tree.2007.12.006.

Charmantier, A., \& Garant, D. (2005). Environmental quality and evolutionary potential: Lessons from wild populations. Proceedings of the Royal Society of London. Series B: Biological Sciences, 272, 1415-1425. doi:10.1098/rspb.2005.3117.

Christe, P., Møller, A. P., \& de Lope, F. (1998). Immunocompetence and nestling survival in the house martin: The tasty chick hypothesis. Oikos, 83, 175-179. doi:10.2307/3546559.

Christe, P., Møller, A. P., Saino, N., \& de Lope, F. (2000). Genetic and environmental components of phenotypic variation in immune response and body size of a colonial bird, Delichon urbica (the house martin). Heredity, 85, 75-83. doi:10.1046/ j.1365-2540.2000.00732.x.
Christe, P., Oppliger, A., Bancalà, F., Castella, G., \& Chapuisat, M. (2003). Evidence for collective medication in ants. Ecology Letters, 6, 19-22. doi:10.1046/j.1461-0248.2003.00395.x.

Christe, P., Richner, H., \& Oppliger, A. (1996). Of great tits and fleas: Sleep baby sleep. Animal Behaviour, 52, 1087-1092. doi: 10.1006/anbe.1996.0256.

Clayton, D. H., Lee, P. L. M., Tompkins, D. M., Brodie, E. D., III. (1999). Reciprocal natural selection on host-parasite phenotypes. American Naturalist, 154, 261-270. doi:10.1086/303237.

Clayton, D. H., \& Moore, H. (Eds.). (1997). Host-parasite evolution general principles and Avian models. Oxford: Oxford University Press.

Clayton, D. H., Moyer, B. R., Bush, S. E., Jones, T. G., Gardiner, D. W., Rhodes, B. B., et al. (2005). Adaptive significance of avian beak morphology for ectoparasite control. Proceedings of the Royal Society of London. Series B: Biological Sciences, 272, 811-817. doi:10.1098/rspb.2004.3036.

Combes, C. (2001). Parasitism: The ecology and evolution of intimate interactions. Chicago: University of Chicago Press.

de Roode, J. C., Pedersen, A. B., Hunter, M. D., \& Altizer, S. (2008). Host plant species affects virulence in monarch butterfly parasites. Journal of Animal Ecology, 77, 120-126. doi:10.1111/ j.1365-2656.2007.01305.x.

Dybdahl, M. F., \& Krist, A. C. (2004). Genotypic vs condition effects on parasite-driven rare advantage. Journal of Evolutionary Biology, 17, 967-973. doi:10.1111/j.1420-9101.2004.00759.x.

Falconer, D. S., \& Mackay, T. F. C. (1996). Introduction to quantitative genetics. London: Longman.

Ferguson, H. M., \& Read, A. F. (2002). Genetic and environmental determinants of malaria parasite virulence in mosquitoes. Proceedings of the Royal Society of London. Series B: Biological Sciences, 269, 1217-1224. doi:10.1098/rspb.2002.2023.

Gasparini, J., Piault, R., Bize, P., \& Roulin, A. Pre-hatching maternal effects inhibit nestling humoral immune response in the tawny owl. Journal of Avian Biology (in press).

Greischar, M. A., \& Koskella, B. (2007). A synthesis of experimental work on parasite local adaptation. Ecology Letters, 10, 418-434. doi:10.1111/j.1461-0248.2007.01028.x.

Hagemeijer, E. J. M., \& Blair, M. J. (Eds.). (1997). The EBCC atlas of European breeding birds: Their distribution and abundance. London: T \& A D Poyser.

Hamilton, W. D. (1980). Sex versus non-sex versus parasites. Oikos, 35, 282-290. doi: $10.2307 / 3544435$.

Heeb, P., Kölliker, M., \& Richner, H. (2000). Bird-ectoparasite interactions nest humidity and ectoparasite community structure. Ecology, 81, 958-968.

Jaenike, J. (1978). An hypothesis to account for the maintenance of sex within population. Evolutionary Theory, 3, 191-194.

Krasnov, B. R., Khokhlova, I. S., Arakelyan, M. S., \& Degen, A. A. (2005). Is a starving host tastier? Reproduction in fleas parasitizing food-limited rodents. Functional Ecology, 19, 625631. doi:10.1111/j.1365-2435.2005.01015.x.

Laine, A. L. (2008). Temperature-mediated patterns of local adaptation in a natural plant-pathogen metapopulation. Ecology Letters, 11, 327-337. doi:10.1111/j.1461-0248.2007.01146.x.

Lambrechts, L., Chavatte, J. M., Snounou, G., \& Koella, J. C. (2006). Environmental influence on the genetic basis of mosquito resistance to malaria parasites. Proceedings of the Royal Society of London. Series B: Biological Sciences, 273, 1501-1506. doi: 10.1098/rspb.2006.3483.

Little, T. J., \& Ebert, D. (2000). The cause of parasitic infection in natural populations of Daphnia (Crustacea: Cladocera): The role of host genetics. Proceedings of the Royal Society of London. Series B: Biological Sciences, 267, 2037-2042. doi:10.1098/ rspb.2000.1246. 
Lively, C. M. (1999). Migration virulence and the geographic mosaic of adaptation by parasites. American Naturalist, 153, S34-S47. doi:10.1086/303210.

Lively, C. M., \& Dybdahl, M. F. (2000). Parasite adaptation to locally common host genotypes. Nature, 405, 679-681. doi:10.1038/ 35015069.

McCoy, K. D., Boulinier, T., Schjørring, S., \& Michalakis, Y. (2002). Local adaptation of an ectoparasite Ixodes uriae to its seabird host. Evolutionary Ecology Research, 4, 441-456.

Merilä, J. (1996). Genetic variation in offspring condition: An experiment. Functional Ecology, 10, 465-474. doi:10.2307/ 2389939.

Møller, A. P. (1990). Effects of a haematophagous mite on the barn swallow (Hirundo rustica): A test of the Hamilton and Zuck hypothesis. Evolution; International Journal of Organic Evolution, 44, 771-784. doi:10.2307/2409545.

Møller, A. P., Martinelli, R., \& Saino, N. (2004). Genetic variation in infestation with a directly transmitted ectoparasite. Journal of Evolutionary Biology, 17, 41-47. doi:10.1046/j.1420-9101. 2003.00660.x.

Mousseau, T. A., \& Fox, C. W. (1998). The adaptive significance of maternal effects. Trends in Ecology \& Evolution, 13, 403-407. doi:10.1016/S0169-5347(98)01472-4.

Mousseau, T. A., \& Roff, D. A. (1986). Natural selection and the heritability of fitness components. Heredity, 59, 181-197. doi: 10.1038/hdy.1987.113.

Müller, W., Groothuis, T. G., Kasprzik, A., Dijkstra, C., Alatalo, R. V., \& Siitari, H. (2005). Prenatal androgen exposure modulates cellular and humoral immune function of black-headed gull chicks. Proceedings of the Royal Society of London. Series B: Biological Sciences, 272, 1971-1977. doi:10.1098/rspb.2005. 3178.

Petit, C., Hossaert-McKey, M., Perret, P., Blondel, J., \& Lambrechts, M. M. (2002). Blue tits use selected plants and olfaction to maintain an aromatic environment for nestlings. Ecology Letters, 5, 585-589. doi:10.1046/j.1461-0248.2002.00361.x.
Roff, D. A. (1997). Evolutionary quantitative genetics. New York: Chapman Hall.

Roulin, A., Brinkhof, M. W. G., Bize, P., Richner, H., Jungi, T. W., Bavoux, C., et al. (2003). Which chick is tasty to parasites? The importance of host immunology versus parasite life history. Journal of Animal Ecology, 72, 75-81. doi:10.1046/j.13652656.2003.00677.x.

Roulin, A., Christe, P., Dijkstra, C., Durcrest, A. L., \& Jungi, T. W. (2007). Origin-related environmental sex and age determinants of immunocompetence susceptibility to ectoparasites and disease symptoms in the barn owl. Biological Journal of the Linnaean Society, 90, 703-718. doi:10.1111/j.1095-8312.2007.00759.x.

Roulin, A., Gasparini, J., \& Froissart, L. (2008). Pre-hatching maternal effects and the tasty chick hypothesis. Evolutionary Ecology Research, 10, 463-473.

Shaw, D. J., Grenfell, B. T., \& Dobson, A. P. (1998). Patterns of macroparasite aggregation in wildlife host populations. Parasitology, 117, 597-610. doi:10.1017/S0031182098003448.

Sorci, G., Møller, A. P., \& Boulinier, T. (1997). Genetics of hostparasite interactions. Trends in Ecology \& Evolution, 12, 196200. doi:10.1016/S0169-5347(97)01056-2.

Tinsley, M. C., Blanford, S., \& Jiggins, F. M. (2006). Genetic variation in Drosophila melanogaster pathogen susceptibility. Parasitology, 132, 767-773. doi:10.1017/S0031182006009929.

Tschirren, B., Fitze, P. S., \& Richner, H. (2003). Sexual dimorphism in susceptibility to parasites and cell-mediated immunity in great tit nestlings. Journal of Animal Ecology, 72, 839-845. doi: 10.1046/j.1365-2656.2003.00755.x.

Wiehn, J., \& Korpimäki, E. (1998). Resource levels reproduction and resistance to haematozoan infections. Proceedings of the Royal Society of London. Series B: Biological Sciences, 265, 11971201. doi:10.1098/rspb.1998.0419.

Wolf, J. B., Broodie, E. D., I. I. I., Cheverud, J. M., Moore, A. J., \& Wade, M. J. (1998). Evolutionary consequences of indirect genetic effects. Trends in Ecology \& Evolution, 13, 64-69. doi: 10.1016/S0169-5347(97)01233-0. 